\title{
ELECTRICAL RESISTANCE OF $\operatorname{Pr}_{0.7}\left(\mathrm{Sr}_{0.28} \mathrm{~Pb}_{0.02}\right) \mathrm{MnO}_{3}$ SINGLE CRYSTALS IN FERROMAGNETIC AND PARAMAGNETIC STATE
}

\author{
K. Kalaydjiev, M. Gospodinov, M. Baychev, M. Kirov, Chr. Popov \\ Laboratory of Low Temperatures and Magnetism, \\ G. Nadjakov Institute of Solid State Physics, \\ Bulgarian Academy of Sciences BG-1784 Sofia, Bulgaria \\ (Received February 25, 2002; received in final form December 11, 2002)
}

\begin{abstract}
We studied the temperature dependence of the electric resistivity in single crystal $\mathrm{Pr}_{0.7}\left(\mathrm{Sr}_{0.28} \mathrm{~Pb}_{0.02}\right) \mathrm{MnO}_{3}$ samples in the temperature interval $20 \div 325 \mathrm{~K}$. The results demonstrated a maximum of resistivity at $T=250 \mathrm{~K}$. This maximum was due to the metal-insulator transition related to the ferromagnetic-paramagnetic phase transition.

Key words: colossal magnetoresistance, manganite perovskites, metal-insulator transition.

PACS number(s): 71.30.+h
\end{abstract}

\section{INTRODUCTION}

Metal-insulator transition in manganite perovskites has attracted considerable attention during the last years [1]. It has been established that the metallic state in these materials is ferromagnetic (with the double exchange mechanism responsible for the ferromagnetism), and a variety of insulating states have been found. In many cases application of a magnetic field converts insulating phase into the ferromagnetic metallic (FM) state, resulting in the phenomenon of 'colossal magnetoresistance' (CMR). Recently, it has been demonstrated the microscopic phase separation plays an essential role in the physics of the manganites $[2,3]$. In particular, it results in the apparent perovskite character of the insulatormetal transition when the transition is from the chargeordered insulating to the ferromagnetic metallic state. It is here that the largest changes in resistivity (more than 6 orders of magnitude), and therefore the largest magnetoresistance are observed. The compounds which have been the focus of studies are the manganite perovskites $T_{1-x} D_{x} \mathrm{MnO}_{3}$ where $T$ is a trivalent lanthanide cation (e.g. La) and $D$ is a divalent, e.g. alkaline earth (e.g. $\mathrm{Ca}, \mathrm{Sr}, \mathrm{Ba}$ ), cation. For the end members of the dilution series, $\mathrm{LaMnO}_{3}$ and $\mathrm{CaMnO}_{3}$, the ground state is antiferromagnetic (AF), as expected for spins interacting via the superexchange interaction when the metaloxygen-metal bound angle is close to $180^{\circ}$ [4]. In a certain range of doping $x=0.2 \div 0.4$, the ground state is FM, and paramagnetic-to-ferromagnetic transition is accompanied by a sharp drop in resistivity $\rho(T)$. Interest in these materials has been renewed by the realization that the MR associated with this correlation between magnetization $(M)$ and resistivity $(\rho)$ can be very large, and the basic interaction responsible for the $\rho-M$ correlation was the double-exchange (DE) interaction [5-7] between heterovalent $\left(\mathrm{Mn}^{3+}, \mathrm{Mn}^{4+}\right)$ neighbours. As for the interest in the FM state, much attention has been given to another type of collective state charge order (CO), typically observed for $x>0.3$. At these doping levels $\mathrm{CO}$ can complete with the FM ground state leading to complex electronic phase behaviour as chemical formula is varied [8-10].

\section{SAMPLES AND EXPERIMENTAL METHOD}

Single crystals of $\operatorname{Pr}_{0.7}\left(\mathrm{Sr}_{0.28} \mathrm{~Pb}_{0.02}\right) \mathrm{MnO}_{3}$ were grown by the high temperature solution method (HTSG). The obtained crystals have a relatively small volume $(1 \div 5)$ mm typically. The chemical composition was determined with ED spectrometer. For transport measurements electrical contacts to the samples were made using graphite paste and resistance was measured by the conventional DC four-probe method. The temperature dependence of electrical resistance for samples was determined by means of platinum "Lake Shore" thermometers model PT-103. Their resistance was determined according to the four-point method. The power supply of the thermometers and of the samples was a 120 Current Source, "Lake Shore Cryotronics". The voltage was measured with Autocal Digital Multimeter "Datron Instruments". Electrical resistivity was recorded by a XY recorder SE-780 "Goerz Metrawatt". The error in the determination of $R=f(T)$ was not more than $\pm 2 \%$.

\section{RESULTS AND DISCUSSION}

The results from the measurements of the relative electrical resistivity as a function of temperature in the interval $20 \div 325 \mathrm{~K}$ are shown in Fig. 1 . Because of the significant size of the contacts relative to the crystal size, accurate determination of the resistivity was difficult. For this reason we shall only present $R(T) / R_{20}$ (the ratio of resistivity at certain temperature to the resistivity measured at $20 \mathrm{~K}$ ). It can be observed that the relative resistivity versus $T$ for a single crystal of $\mathrm{Pr}_{0.7}\left(\mathrm{Sr}_{0.28} \mathrm{~Pb}_{0.02}\right) \mathrm{MnO}_{3}$ was maximal. In the interval $20 \div 250 \mathrm{~K}$, the samples demonstrated a metal dependence $R=f(T)$, while at temperatures $250 \mathrm{~K}$ their resistance was similar to that of 
dielectrics. Similar measurements of magnetoresistance associated with transition from paramagnetic (PM) insulator to FM metal were performed by Searle and Wang on $\mathrm{La}_{1-x} \mathrm{~Pb}_{x} \mathrm{MnO}_{3}$ [11]. Substitution on the La site modifies the phase behaviour through size effects, and can be found in $\mathrm{Pr}_{0.5} \mathrm{Sr}_{0.5} \mathrm{MnO}_{3}[8]$ and $\mathrm{Pr}_{0.7}(\mathrm{Sr}, \mathrm{Ca})_{0.3} \mathrm{MnO}_{3-\delta}$ $[12,13]$.

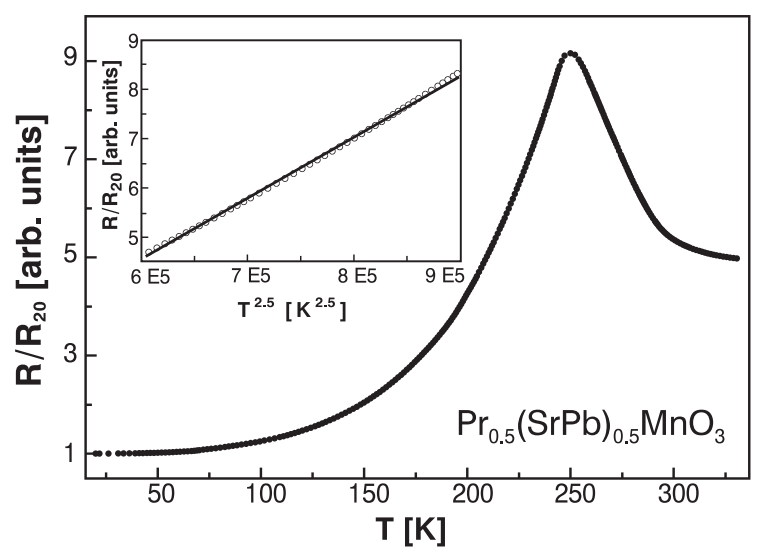

Fig. 1. Ralative resistivity versus $T$ for a single cristals of $\mathrm{Pr}_{0.5} \mathrm{SrPb}_{0.5} \mathrm{MnO}_{3}$. The insert shows the low-temperature relative resistivity compared to $T^{2.5}$ behaviour typical for the ferromagnetic state.

The compound studied, which included the end member $\mathrm{LaMnO}_{3}$, were isostructural, crystallizing in the orthorhombic $P_{n m a}$ structure at room temperature. The end member $\mathrm{LaMnO}_{3}$ was very distorted: the octahedra were elongated and tilted. Though titling distortions are not unusual for perovskites simply on the basis of steric conditions, its magnitude in $\mathrm{LaMnO}_{3}$ and the presence of elongation are thought to be the result of Jahn-Teller local distortion [14, 15]. By using mixtures of $T=\mathrm{La}$, $\mathrm{Pr}$ and $\mathrm{Nd}$ and $D=\mathrm{Ca}, \mathrm{Ba}$ and $\mathrm{Pb}, x$ can be varied, with the result that the perovskite structure is stable for $0.85<x<0.91$ [16]. At finite doping, charge balance is maintained by a fraction, $x$, a Mn ions assuming a tetravalent, $\mathrm{Mn}^{4+}\left(d^{3}\right)$, configuration in a random fashion throughout the crystal, with the remainder in the $\mathrm{Mn}^{3+}\left(d^{4}\right)$ state. Van Santen and Jonker showed [17] that at temperature above the ferromagnetic Curie point, $T_{c}$, the resistivity behaves like a semiconductor $d \rho / d T<0$, but that below $T_{c}$, not only is there a sharp reduction in resistivity, but, also a transition to metallic behaviour, $d \rho / d T>0$. Similar behaviour have $\mathrm{La}_{1-x} \mathrm{Sr}_{x} \mathrm{MnO}_{3}$ and $\mathrm{La}_{1-x} \mathrm{Ca}_{x} \mathrm{MnO}_{3}$ [18]. Zener [19] proposed a mechanism he called 'double exchange' (DE) to explain the simultaneous occurrence of ferromagnetism and metallicity, both as a function of $x$ and $T$. For $x<0.5$ the majority of Mn ions are in the $d^{4}$ configuration, which, for octahedral coordination, means a half-filled $t_{2 g}$ triplet and quarterfilled eg doublet. The minority of sites is $d^{3}$, which corresponds to a half-filled $t_{2 g}$ orbital triplet. This hopping is impeded if neighbouring sites are orthogonal, i.e., spins are not parallel. Anderson and Hasegawa showed that the transfer integral varies as cosine of the angle between neighbouring spins [20]. As temperature is lowered and spin fluctuations decrease, the combined itinerant localmoment systems lowers its total energy by aligning the spins ferromagnetically and allowing the itinerant electrons to gain kinetic energy. Recently, Millis et al. have shown that Hamiltonian incorporating only the DE interaction cannot explain the most obvious feature of the manganites, namely the magnitude of the charge in resistivity at the FM transition [21]. They, as well as Roder et al. proposed, in addition to DE, an electron-phonon coupling term [22, 23]. Such an interaction is not unexpected in a picture where transport is via hopping among $\mathrm{Mn}^{3+}$ and $\mathrm{Mn}^{4+}$ ions. Here, the hole, corresponding to a $\mathrm{Mn}^{4+}\left(d^{3}\right)$ ion must displace a $\mathrm{Mn}^{3+}\left(d^{4}\right)$ ion. Which, in the dilute limit, can be associated with a large JahnTeller (J-T) coupling.

\section{CONCLUSIONS}

Our investigations on the temperature dependence of the electric resistivity in single crystal $\operatorname{Pr}_{0.7}\left(\mathrm{Sr}_{0.28} \mathrm{~Pb}_{0.02}\right) \mathrm{MnO}_{3}$ demonstrated a metalinsulator transition at Curie point temperature $T_{c}=$ $250 \mathrm{~K}$, due to the deviation of octahedral oxygen environment. This distortion has a similar magnitude as that in $\mathrm{LaMnO}_{3}$ and, most likely, arises from the manifestation of the strong electron-phonon coupling by the J-T theorem in the dilute case. Even though the J-T theorem applies strictly only for single ions, an electronphonon coupling may also play a significant role for the interaction of ions.
[1] Collosal Magnetoresistance Oxides, ed. by Y. Tokura, (Gordon and Breach, London, 1999).

[2] M. Uchara, S. Mori, C. H. Chen, S. W. Cheong, Nature (London), 339, 500 (1999).

[3] N. A. Babushkina, L. M. Belova, D. I. Khomskii, K. I. Rugel, O. Yu. Gorbenko, A. R. Kanl, Phys. Rev. B 59, 6994 (1999).

[4] J. B. Goodenough, Magnetism and the Chemical Bond (Huntington, Krieger, 1976).

[5] C. Zener, Phys. Rev. 81, 440 (1951).
[6] P. W. Anderson, H. Hasegawa, Phys. Rev. 100, 675 (1955).

[7] P. G. De Genes, Phys. Rev. 118, 141 (1960).

[8] Y. Tomioka, A. Asamitsu, Y. Maritomo, H Kuwahara, Y. Tokura, Phys. Rev. 74, 5108 (1953).

[9] E. O. Wolan, W. C. Koehler, Phys. Rev. 100, 545 (1955).

[10] A. P. Ramirez, P. Schiffer, S. W. Cheong, W. Bao, T. T. M.Palstra, P. L. Gammel, D. J. Bishop, B. Zegarski, Phys. Rev. Lett. 76, 3188 (1996).

[11] C. W. Seatle, S. T. Wong, Can. J. Phys. 47, 2703 (1969). 
[12] B. Raveau, A. Maignan, V. Caignaert, J. Solid State Chem. 117, 424 (1995).

[13] A. Maignan, Ch. Simon, V. Caignaert, B. Raveau, J. Magn. Mater. 152, L5 (1996).

[14] A. A. B. J. Elemans, B. Von Laar, K. R. Van Der Veer, B. O. Loopstra, J. Solid State Chem. 3, 238 (1971).

[15] B. J. Goodenough, Phys. Rev. 100, 564 (1955).

[16] G. H. Jonker, J. H. Van Santen, Physica 16, 337 (1950).

[17] J. H. Van Santen, G. H. Jonker, Physica 16, 599 (1950).

[18] A. Urushibara, Y. Moritomo, T. Arima, A. Asamitsu, G. Kido, Y. Tokura, Phys. Rev. B 51, 14103 (1995).

[19] C. Zener, Phys. Rev. 81, 440 (1951).

[20] P. W. Anderson, H. Hasegawa, Phys. Rev. 100, 675
(1955).

[21] A. J. Millis, P. B. Littlewood, B. I. Shraiman, Phys. Rev. Lett. 74, 5144 (1995).

[22] A. J. Millis, B. I. Shraiman, R. Mueller, Phys. Rev. Lett. 77, 175 (1996).

[23] H. Roder, J. Zhang, A. R. Bishop, Phys. Rev. Lett. 76, 1356 (1996).

[24] I. K. Moon, D. I. Jung, K. B. Lee, Y. I. Jeong, Appl. Phys. Lett. 76, 2451 (2000).

[25] V. Podzorov, M. Uehara, M. E. Gershenson, T. Y. Koo, S. W. Cheong, Phys. Rev. B 61, 3781 (2000).

[26] B. Raquet, A. Anane, S. Wirth. P. Xiong, S. von Molnar, Phys. Rev. Lett. 84, 4485 (2000).

\title{
ЕЛЕКТРИЧНИЙ ОПІР МОНОКРИСТАЛІВ $\mathbf{P r}_{0.7}\left(\mathbf{S r}_{0.28} \mathbf{P b}_{0.02}\right) \mathrm{MnO}_{3}$ У ФЕРОМАГНЕТНОМУ ТА ПАРАМАГНЕТНОМУ СТАНАХ
}

\author{
K. Калайджієв, М. Господінов, М. Байчев, М. Кіров, Х. Попов \\ Лабораторія низьких температур і магнетизму, \\ Інститут фізики твердого тіла імені Г. Наджакова, \\ Софія, BG-1784, Болгарія
}

\begin{abstract}
Вивчено температурну залежність електричного опору в зразках монокристалів $\operatorname{Pr}_{0.7}\left(\operatorname{Sr}_{0.28} \mathrm{~Pb}_{0.02}\right) \mathrm{MnO}_{3}$ в температурному інтервалі $20 \div 325 \mathrm{~K}$. Результати вказують на максимальне значення опору відбувається при $T=250 \mathrm{~K}$. Цей максимум пов'язаний з переходом метал-діелектрик, що співвідноситься з фазовим переходом феромагнетик-парамагнетик.
\end{abstract}

